\title{
Levels of anxiety and depression as predictors of mortality: the HUNT study
}

Arnstein Mykletun, Ottar Bjerkeset, Simon Øverland, Martin Prince, Michael Dewey and Robert Stewart

\section{Background}

Depression is reported to be associated with increased mortality, although underlying mechanisms are uncertain. Associations between anxiety and mortality are also uncertain.

\section{Aims}

To investigate associations between individual and combined anxiety/depression symptom loads (using the Hospital Anxiety and Depression Scale (HADS)) and mortality over a 3-6 year period.

\section{Method}

We utilised a unique link between a large population survey (HUNT-2, $n=61349$ ) and a comprehensive mortality database.

\section{Results}

Case-level depression was associated with increased mortality (hazard ratio $(\mathrm{HR})=1.52,95 \% \mathrm{Cl} 1.35-1.72$ ) comparable with that of smoking $(\mathrm{HR}=1.59,95 \% \mathrm{Cl}$ 1.44-1.75), and which was only partly explained by somatic symptoms/conditions. Anxiety comorbid with depression lowered mortality compared with depression alone (anxiety depression interaction $P=0.017$ ). The association between anxiety symptom load and mortality was U-shaped.

\section{Conclusions}

Depression as a risk factor for mortality was comparable in strength to smoking. Comorbid anxiety reduced mortality compared with depression alone. The relationship between anxiety symptoms and mortality was more complex with a U-shape and highest mortality in those with the lowest anxiety symptom loads.

\section{Declaration of interest}

None.
Depression is repeatedly reported to increase mortality, ${ }^{1,2}$ but the strength of this association and the issue of residual confounding (e.g. by lifestyle factors and physical disease) remain controversial., Even less is known about how anxiety affects mortality, with reports of both positive and negative effects. ${ }^{5,6}$ We have previously found that depression is associated both with cardiovascular and other-cause mortality to a similar extent. ${ }^{7}$ Employing the same record linkage between a large population health survey and a national mortality registry, we sought to expand this analysis by: comparing case-level anxiety, depression and comorbid anxiety and depression as predictors; investigating the underlying shape of the associations with individual symptom counts; and investigating the role of potential mediating, confounding and modifying factors.

\section{Method}

\section{Study design and end-point (mortality)}

Nord-Trøndelag County is one of 19 in Norway, and is broadly representative of the national population, although slightly less urban and with lower educational attainment. The HUNT-2 study was carried out from August 1995 until June 1997. Inhabitants $(n=93138)$ in Nord-Trøndelag County aged $>19$ years (mean age 48.8 years, s.d. $=16.7$ ) received a mailed questionnaire and invitation to a clinical examination, and 61349 individuals $(66 \%)$ provided sufficient data for this analysis. Non-responders were heterogeneous but did, on average, have poorer health than participants. ${ }^{8}$

Baseline data were obtained from the Health Study of Nord-Trøndelag County (HUNT-2), and have been used for one previous study of mortality in relation to anxiety and depression in the general population. ${ }^{7}$ A subsample defined by the upper one percentile on the Hospital Anxiety and Depression
Scale $(\mathrm{HADS})^{9}$ total score was the target of an intervention in the form of letters advising the individual and his/her general practitioner to consider treatment for the high symptom score, ${ }^{10}$ and the mortality in this subgroup has been described elsewhere. ${ }^{11}$

Data on mortality was obtained from the National Mortality Registry from date of attendance until December 2000 with a mean follow-up of 4.4 years (s.d. $=0.68$ ). This is a relatively short follow-up, but combined with a large sample size, the study is generously powered.

\section{Exposures: anxiety and depressive symptoms}

The HADS is a self-report questionnaire comprising 14 four-point Likert-scaled items covering anxiety (HADS-A) and depression (HADS-D) over the past 2 weeks. ${ }^{9}$ It was specifically designed to avoid false-positive cases when administered in general hospital settings and so contains no items on somatic symptoms or sleep or appetite disturbance, focusing instead on the psychological and cognitive symptoms. Symptoms of anhedonia are central to the depression subscale, whereas the symptoms assessed by the anxiety subscale are mostly related to generalised anxiety, with a focus on feelings of being tense and being frightened, of worrying thoughts, restlessness and one item on panic. ${ }^{12}$ A cut-off score of 8 on each subscale has been found to screen adequately (sensitivity and specificity both about 0.80 ) for case-level depression and anxiety according to DSM-III $I^{13} / \mathrm{IV}^{14}$ and $\mathrm{ICD}-8^{15} / 9^{16}$ diagnostic criteria. ${ }^{17}$ Principal components analysis has indicated good discrimination between the two subscales in this sample. ${ }^{12}$ Employing these cut-offs, four groups were identified for the analysis presented here: case-level anxiety only, case-level depression only, case-level comorbid anxiety and depression, and a reference group scoring below case-level on both scales. ${ }^{7}$ Anxiety and depression scale scores were also encoded in quartiles, 
as continuous measures, with multiple cut-offs within the clinical range, and as quadratic terms.

\section{Confounding factors}

Potential confounding and mediating factors were operationalised in accordance with our previous publication on associations between mental disorder and cause-specific mortality. ${ }^{7}$ Because of the cross-sectional nature of the baseline survey, no attempt was made to distinguish confounding and mediating (causal pathway) factors in the analysis.

Physical health was assessed by self-report by 'ticking boxes' for somatic diagnoses and somatic symptoms: a sum of somatic diagnoses comprising angina pectoris, asthma, cancer, diabetes, epilepsy, hypertension, myocardial infarction, musculoskeletal diseases, respiratory disease, stroke and thyroid diseases was computed. Based on the un-standardised regression coefficients from logistic regression models, each of these diagnoses were weighted according to the strength of their association with mortality to better capture differential severity of the various symptoms and diagnoses and provide a more accurate covariate for the analysis in question. Diagnoses negatively associated with mortality (hypothyroid disease, goitre, fibromyalgia, osteoarthritis and ankylosing spondylitis) were omitted. (These negative associations were not hypothesised, might be confounded and might be the subject of investigation in future studies.)

Similarly, a mortality-weighted index for somatic symptoms was computed as the number of organ systems for which symptoms were reported, comprising gastrointestinal (four questions on nausea, heartburn, diarrhoea and constipation), sensation (two questions on hearing and sight), heart (one question on palpitations) and respiratory function (one on respiratory problems). Musculoskeletal symptoms (11 body areas) and headaches (two items) were negatively associated with mortality and were not included in the index.

An ordinal index of physical impairment was computed from four questions on self-evaluated moderate or severe impairments from somatic disease, reduced locomotivity, hearing and sight.

Self-rated health-related behaviours included in the analysis were: smoking (current, former and never smoker), ${ }^{18}$ physical activity (three levels), and $\mathrm{CAGE}^{19}$ caseness for alcohol problems. ${ }^{20}$ The two latter variables were obtained from a separate questionnaire with an about $20 \%$ lower response rate; missing responses were encoded as a separate category.

Educational level was coded according to compulsory, secondary and university level. ${ }^{21}$ Socioeconomic status was measured according to the Erikson-Goldthorpe-Portocareros scheme, which is based on occupational information. ${ }^{22}$

Physical measures of body mass index (BMI), resting systolic and diastolic blood pressure ${ }^{23}$ and non-fasting total cholesterol were obtained by a specially trained nurse during the screening, and all these variables were encoded in quartiles as analyses of these variables' associations with mortality indicated non-linear associations.

\section{Statistical analysis}

Logistic regression models were used to quantify associations between anxiety, depression and mortality, for investigation of confounding/mediating factors, and for testing interaction terms. All associations reported were statistically significant $(P<0.05)$ using two-tailed tests, unless otherwise stated. All models were adjusted for age (encoded categorically in decades) and gender. All covariates were entered as categorical variables, with the exception of those for the somatic symptom scale, which were encoded as a continuous variable. Results are presented as odds ratios (OR) with 95\% CI. Individuals still alive at end of followup comprised a common reference category. The proportional hazards assumption was not violated in any analysis (exposures' effects on outcome did not vary with time), and the same conclusions were reached applying Cox regression analysis, and illustrated with survival plots. For the purpose of comparison of effect sizes, survival plots were produced also for daily smoking. The association between the exposures and mortality was also described in terms of population attributable fractions to illustrate the proportion of incident cases in the population that would have been prevented if a causal exposure were removed, assuming an unconfounded causal association. ${ }^{24}$

\section{Ethics}

HUNT-2 was approved by the National Data Inspectorate and the Board of Research Ethics in Health Region IV of Norway.

\section{Results}

\section{Population characteristics}

The participation rate in the HUNT-2 study was $66 \%$. Nonparticipants were older, more likely to be institutionalised or in hospitals and the mortality rate during follow-up in nonparticipants was higher than in participants (15\% v. 4\%). The following results are based on 2309 deaths among 61349 participants with valid data.

Mortality was associated with increasing age and male gender. Adjusted for age and gender, mortality was significantly associated with physical impairment, low physical activity, smoking, alcohol problems as elicited on the CAGE questionnaire, increased numbers of somatic diagnoses and symptoms, lower educational level and lower socioeconomic status scores. Blood pressure, total cholesterol level and BMI were associated with mortality, with highest mortality in the lowest quartile of all these variables (data not shown).

\section{Associations between case-level anxiety/depression and mortality}

Adjusted for age and gender only, depression caseness alone was more strongly associated with mortality $(\mathrm{OR}=1.68)$ than anxiety caseness $(\mathrm{OR}=1.19)$ or comorbid anxiety/depression $(\mathrm{OR}=1.44)$. The interaction term between case-level anxiety and case-level depression was significant and negative (step chi-squared test $P=0.017$ by adding the interaction term to a model comprising anxiety, depression, age and gender), reflecting the lower risk in the comorbid group than anticipated from the individual odds ratios. Cox regression models showing the same are presented in Fig. 1.

To illustrate the strength of the association of depression and mortality, we compared it to that of smoking (Fig. 1). Adjusted for age and gender only, the association between depression alone and mortality (hazard ratio $(\mathrm{HR})=1.52$, 95\% CI 1.35-1.72) was comparable with that of current smoking $(\mathrm{HR}=1.59,95 \% \mathrm{CI}$ 1.44-1.75), compared with former and never smokers combined. Fully adjusted, the difference was somewhat stronger in smoking $(\mathrm{HR}=1.42,95 \%$ CI 1.29-1.58) compared with depression ( $\mathrm{HR}=1.27$, 95\% CI 1.12-1.43), but confidence intervals were overlapping.

The effects of separate and cumulative adjustments for covariates on the associations of anxiety and depression with mortality are displayed in Table 1 in the order of apparent influence. Strongest attenuation of the associations of interest was found by adjusting for somatic symptoms and diagnoses 


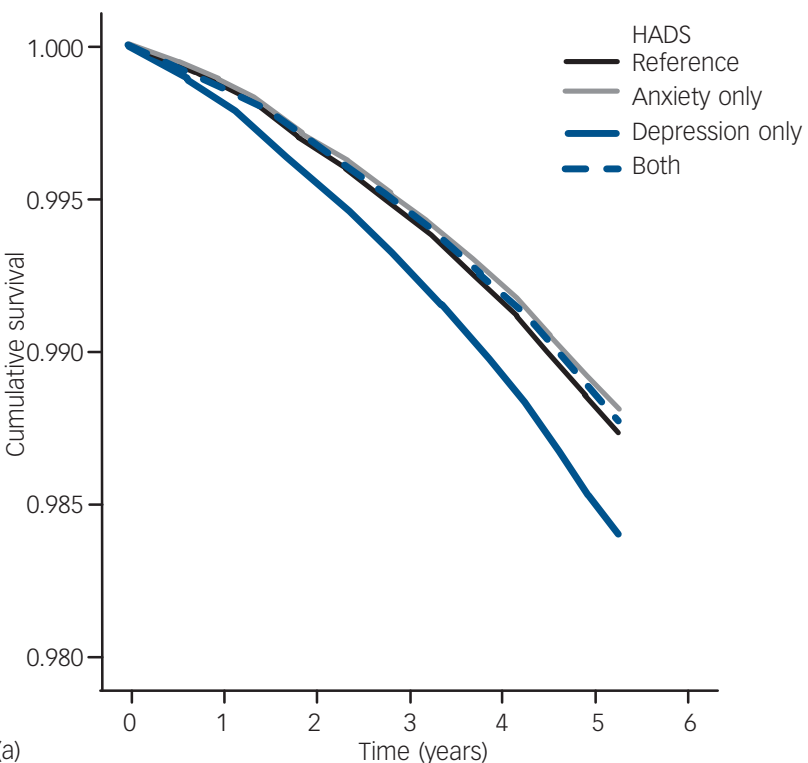

Hazard ratios from Cox regression models:

Adjusted for age and gender only: Reference (no anxiety/depression) Anxiety only

Depression only

Comorbid anxiety and depression

1.00

$1.15(95 \% \mathrm{Cl} 0.98-1.36)$

$1.52(95 \% \mathrm{Cl} 1.35-1.72)$

$1.32(95 \% \mathrm{Cl} 1.14-1.54)$

Fully adjusted model as in Table 1 (last row):

Reference (no anxiety/depression) 1.00

Anxiety only

Depression only

$0.94(95 \% \mathrm{Cl} 0.80-1.11)$

$1.27(95 \% \mathrm{Cl} 1.12-1.43)$

Comorbid anxiety and depression $\quad 0.97(95 \% \mathrm{Cl} 0.83-1.14)$

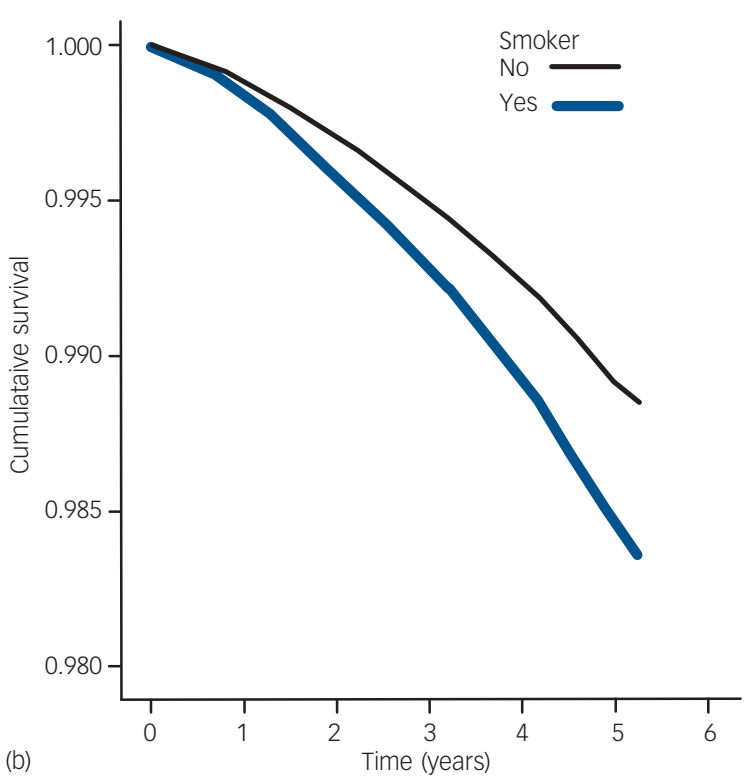

Hazard ratios from Cox regression models:

Adjusted for age and gender only:

Reference (former/never) $\quad 1.00$

current smoker

$1.59(1.44-1.75)$

Fully adjusted model as in Table 1 (last row):

Reference (former/never) $\quad 1.00$

current smoker $1.42(1.29-1.58)$

Fig. 1 Cox regression models for (a) anxiety only, depression only or both as risk factors for mortality and (b) comparision with current daily smoking. Both survival curves based on fully adjusted models. HADS, Hospital Anxiety and Depression Scale.

(accounting for most of the mortality association with anxiety $(\mathrm{OR}=1.04,95 \%$ CI $0.86-1.24)$ and about one-fifth of the association with depression $(\mathrm{OR}=1.53,95 \%$ CI 1.33-1.76)). Self-reported diagnoses accounted for far more of this attenuation than did somatic symptoms. Reported physical impairment was the second strongest covariate, followed by physical activity.
Adjustment for smoking and alcohol problems, educational level and socioeconomic status, BMI, diastolic blood pressure and cholesterol level had only marginal effects on the associations of interest. Adjustment for all the above-mentioned factors simultaneously entirely accounted for the associations of anxiety alone $(\mathrm{OR}=0.95,95 \%$ CI $0.79-1.14)$ and comorbid anxiety/depression

Table 1 Mortality as a function of anxiety and depression with adjustment for potential confounding and mediating factors (odds ratios from logistic regression analyses)

\begin{tabular}{|c|c|c|c|c|c|c|c|c|c|c|c|c|}
\hline & \multicolumn{6}{|c|}{ Cumulative adjustments } & \multicolumn{6}{|c|}{ Adjustments entered separately ${ }^{a}$} \\
\hline & \multicolumn{2}{|c|}{$\begin{array}{c}\text { Anxiety } n=5864 \\
\text { (9.6\%) whereof } \\
n=162 \text { died }\end{array}$} & \multicolumn{2}{|c|}{$\begin{array}{c}\text { Depression } n=3032 \\
(4.9 \%) \text { whereof } \\
n=331 \text { died }\end{array}$} & \multicolumn{2}{|c|}{$\begin{array}{c}\text { Both } n=3640 \\
(5.9 \%) \text { whereof } \\
n=190 \text { died }\end{array}$} & \multicolumn{2}{|c|}{$\begin{array}{c}\text { Anxiety } n=5864 \\
(9.6 \%) \text { whereof } \\
n=162 \text { died }\end{array}$} & \multicolumn{2}{|c|}{$\begin{array}{c}\text { Depression } n=3032 \\
\text { (4.9\%) whereof } \\
n=331 \text { died }\end{array}$} & \multicolumn{2}{|c|}{$\begin{array}{c}\text { Both } n=3640 \\
(5.9 \%) \text { whereof } \\
n=190 \text { died }\end{array}$} \\
\hline & OR & $(95 \% \mathrm{Cl})$ & OR & $(95 \% \mathrm{Cl})$ & OR & $(95 \% \mathrm{Cl})$ & OR & $(95 \% \mathrm{Cl})$ & OR & $(95 \% \mathrm{Cl})$ & OR & $(95 \% \mathrm{Cl})$ \\
\hline Age and gender & 1.19 & $(1.00-1.42)$ & 1.68 & $(1.46-1.92)$ & 1.44 & $(1.22-1.70)$ & 1.19 & $(1.00-1.42)$ & 1.68 & $(1.46-1.92)$ & 1.44 & $(1.22-1.70)$ \\
\hline $\begin{array}{l}\text { Somatic symptoms } \\
\text { and diagnoses }\end{array}$ & 1.04 & $(0.86-1.24)$ & 1.53 & $(1.33-1.76)$ & 1.21 & $(1.02-1.44)$ & 1.04 & $(0.86-1.24)$ & 1.53 & $(1.33-1.76)$ & 1.21 & $(1.02-1.44)$ \\
\hline Physical impairment & 1.00 & $(0.83-1.20)$ & 1.46 & $(1.27-1.68)$ & 1.14 & $(0.96-1.35)$ & 1.09 & $(0.91-1.30)$ & 1.53 & $(1.33-1.75)$ & 1.25 & $(1.06-1.49)$ \\
\hline Physical activity & 1.00 & $(0.83-1.19)$ & 1.41 & $(1.22-1.62)$ & 1.10 & $(0.92-1.30)$ & 1.18 & $(0.99-1.40)$ & 1.58 & $(1.38-1.82)$ & 1.35 & $(1.14-1.60)$ \\
\hline $\begin{array}{l}\text { Smoking, alcohol, } \\
\text { physical activity }\end{array}$ & 0.97 & $(0.81-1.67)$ & 1.40 & $(1.21-1.61)$ & 1.05 & $(0.88-1.25)$ & 1.16 & $(0.97-1.38)$ & 1.66 & $(1.44-1.90)$ & 1.37 & $(1.16-1.62)$ \\
\hline $\begin{array}{l}\text { Educational level } \\
\text { and SES }\end{array}$ & 0.97 & $(0.81-1.16)$ & 1.38 & $(1.20-1.59)$ & 1.04 & $(0.87-1.24)$ & 1.17 & $(0.99-1.40)$ & 1.64 & $(1.43-1.88)$ & 1.40 & $(1.18-1.65)$ \\
\hline Physical measures ${ }^{b}$ & 0.95 & $(0.79-1.14)$ & 1.37 & $(1.19-1.58)$ & 1.02 & $(0.86-1.22)$ & 1.17 & $(0.98-1.40)$ & 1.67 & $(1.45-1.91)$ & 1.42 & $(1.20-1.68)$ \\
\hline $\begin{array}{l}\text { Adjustment for all } \\
\text { factors above }\end{array}$ & 0.95 & $(0.79-1.14)$ & 1.37 & $(1.19-1.58)$ & 1.02 & $(0.86-1.22)$ & 0.95 & $(0.79-1.14)$ & 1.37 & $(1.19-1.58)$ & 1.02 & $(0.86-1.22)$ \\
\hline $\begin{array}{l}\text { SES, socioeconomic sta } \\
\text { a. All models are adjust } \\
\text { b. Body mass index, dia }\end{array}$ & for a & tegorically in & decade & $\begin{array}{l}\text { d gender. } \\
\text { rol level. }\end{array}$ & & & & & & & & \\
\hline
\end{tabular}


$(\mathrm{OR}=1.02,95 \%$ CI $0.86-1.22)$ with mortality, but a substantial proportion of the association between depression alone and mortality remained unexplained ( $\mathrm{OR}=1.37,95 \%$ CI 1.19-1.58).

The association between anxiety and mortality was U-shaped, with increased mortality in both the lowest and highest quartiles of the distribution compared with the third quartile (Table 2, column 1). The population attributable fraction for low anxiety levels (first quartile $n=22112$ ) was 0.077 in the fully adjusted model based on the entire sample.

This non-monotonic association was statistically significant as tested by adding a quadratic anxiety term to a regression model containing anxiety (continuous variable) and other variables as specified in Table 3. The findings were robust for all adjustments. Testing for monotonic trends in the association between anxiety and mortality (anxiety encoded as a continuous variable) revealed a negative association in the fully adjusted models regardless of comorbid depression. These findings (U-shape and negative monotonic trends) were attenuated, but remained significant in those with depression (Table 2, columns 2 and 3 ).

With respect to depressive symptoms, the association with mortality was only apparent for the fourth quartile of scale scores, giving rise to significant positive linear and quadratic terms in fully adjusted models (Table 3, column 1). These findings were also robust when stratified by case-level anxiety (Table 3 , columns 2 and 3). With scale scores of $0-7$ as a reference group, a dose-response association was found for the depression mortality association (Table 4) (scale score 8-10 $(n=332), \mathrm{OR}=1.27,95 \%$ CI $1.10-1.46)$; scale score $11-14(n=157), \mathrm{OR}=1.43,95 \%$ CI $1.16-1.75$; and scale score $15-21 \quad(n=32), \mathrm{OR}=1.71,95 \% \mathrm{CI}$

\begin{tabular}{|c|c|c|c|}
\hline & $\begin{array}{l}\text { Entire sample } \\
(n=61349)\end{array}$ & $\begin{array}{l}\text { Excluding case-level } \\
\text { depression }(n=54677)\end{array}$ & $\begin{array}{l}\text { Including only case-level } \\
\text { depression }(n=6672)\end{array}$ \\
\hline \multicolumn{4}{|l|}{ Adjusted for age and gender } \\
\hline HADS-A score 0-2 $(n=22112$ whereof $n=1040$ died $)$ & $1.14^{*}$ & $1.35^{\star}$ & 1.17 \\
\hline HADS-A score 3-4 ( $n=14,752$ whereof $n=460$ died) & 1.02 & $1.20 *$ & 0.78 \\
\hline HADS-A score 5-6 ( $n=10983$ whereof $n=328$ died) & 1.00 (ref) & 1.00 (ref) & 1.00 (ref) \\
\hline HADS-A score 7-21 ( $n=13502$ whereof $n=481$ died $)$ & $1.25^{\star}$ & $1.38^{*}$ & $0.75^{\star}$ \\
\hline Model significance, ${ }^{b} P$ & 0.007 & $<0.001$ & 0.007 \\
\hline Significance (linear), ${ }^{\mathrm{C}} \mathrm{P}$ & $0.043(+)$ & $0.273(-)$ & $0.239(-)$ \\
\hline Significance (quadratic), ${ }^{d} P$ & $<0.001$ & 0.010 & $<0.001$ \\
\hline \multicolumn{4}{|l|}{ Fully adjusted } \\
\hline HADS-A score 0-2 $(n=22112$ whereof $n=1040$ died $)$ & $1.27^{\star}$ & $1.48^{*}$ & 1.14 \\
\hline HADS-A score 3-4 ( $n=14752$ whereof $n=460$ died) & 1.07 & $1.26^{*}$ & 0.80 \\
\hline HADS-A score 5-6 ( $n=10983$ whereof $n=328$ died $)$ & 1.00 (ref) & 1.00 (ref) & 1.00 (ref) \\
\hline HADS-A score 7-21 ( $n=13502$ whereof $n=481$ died) & 1.07 & $1.23^{*}$ & $0.66^{*}$ \\
\hline Model significance, ${ }^{b} P$ & 0.001 & $<0.001$ & 0.001 \\
\hline Significance (linear), ${ }^{\mathrm{C}} \mathrm{P}$ & $0.009(-)$ & $<0.001(-)$ & $0.010(-)$ \\
\hline Significance (quadratic), ${ }^{d} P$ & 0.001 & 0.057 & 0.009 \\
\hline \multicolumn{4}{|c|}{$\begin{array}{l}\text { HADS-A, Hospital Anxiety and Depression Scale, anxiety items; ref, reference data. } \\
\text { a. Linear models are indicated (+) for positive effects and (-) for negative effects. } \\
\text { b. Step chi-squared significance by adding anxiety (encoded in quartiles) to the other variables in the model. } \\
\text { C. Step chi-squared significance by adding anxiety (encoded as a continuous variable) to the other variables in the model (not including the quadratic term for scale score anxiety). } \\
\text { d. Step chi-squared significance by adding the quadratic anxiety term (continuous variable) to all other variables, including anxiety (also included as a continuous variable). } \\
\text { e. Adjusted for all factors reported in Table } 1 \text {. }\end{array}$} \\
\hline
\end{tabular}

Table 3 Mortality as a function of depression (encoded in quartiles), stratified for case-level anxiety. Results from logistic regression analyses (odds ratios) ${ }^{\mathrm{a}}$

\begin{tabular}{|c|c|c|c|}
\hline & $\begin{array}{l}\text { Entire sample } \\
\qquad(n=61349)\end{array}$ & $\begin{array}{l}\text { Excluding case-level } \\
\text { anxiety }(n=51845)\end{array}$ & $\begin{array}{l}\text { Including only case-level } \\
\text { anxiety }(n=9504)\end{array}$ \\
\hline \multicolumn{4}{|l|}{ Adjusted for age and gender } \\
\hline HADS-D score 0-2 ( $n=19848$ whereof $n=458$ died $)$ & 1.00 (ref) & 1.00 (ref) & 1.00 (ref) \\
\hline HADS-D score 2-3 ( $n=16610$ whereof $n=477$ died) & 1.00 & 0.97 & $3.66^{*}$ \\
\hline HADS-D score $4-5(n=11,016$ whereof $n=460$ died $)$ & 1.14 & 1.11 & $3.31^{*}$ \\
\hline HADS-D score 6-21 ( $n=13875$ whereof $n=914$ died) & $1.51^{*}$ & $1.47^{*}$ & $4.22^{*}$ \\
\hline Model significance, ${ }^{\mathrm{b}} P$ & $<0.001$ & $<0.001$ & 0.013 \\
\hline Significance (linear), ${ }^{\mathrm{C}} \mathrm{P}$ & $<0.001(+)$ & $<0.001(+)$ & $0.002(+)$ \\
\hline \multicolumn{4}{|l|}{ Fully adjusted $^{d}$} \\
\hline HADS-D score 0-1 $(n=19848$ whereof $n=458$ died $)$ & 1.00 (ref) & 1.00 (ref) & 1.00 (ref) \\
\hline HADS-D score 2-3 ( $n=16610$ whereof $n=477$ died) & 0.95 & 0.92 & $3.54^{\star}$ \\
\hline HADS-D score $4-5$ ( $n=11016$ whereof $n=460$ died) & 1.03 & 1.02 & 3.30 \\
\hline HADS-D score 6-21 ( $n=13875$ whereof $n=914$ died) & $1.21 *$ & $1.23^{*}$ & $4.12^{\star}$ \\
\hline Model significance, ${ }^{b} P$ & 0.001 & $<0.001$ & 0.025 \\
\hline Significance (linear), ${ }^{\mathrm{C}} P$ & $<0.001(+)$ & $<0.001(+)$ & $0.023(+)$ \\
\hline \multicolumn{4}{|c|}{$\begin{array}{l}\text { HADS-D, Hospital Anxiety and Depression Scale, depression items; ref, reference data. } \\
\text { a. Linear models are indicated ( }+ \text { ) for positive effects and (-) for negative effects. } \\
\text { b. Step chi-squared significance by adding depression (encoded in quartiles) to the other variables in the model. } \\
\text { c. Step chi-squared significance by adding depression (encoded as a continuous variable) to the other variables in the model. } \\
\text { d. Adjusted for all factors reported in Table } 1 \text {. } \\
\star P<0.05 \text {. }\end{array}$} \\
\hline
\end{tabular}


Table 4 Dose-response association between anxiety and depression and mortality

\begin{tabular}{|c|c|c|c|c|c|c|c|}
\hline & Score & $n$ & $\begin{array}{c}\text { Dead, } \\
n\end{array}$ & $\begin{array}{l}\text { OR }(95 \% \mathrm{Cl}) \text {, } \\
\text { adjusted for age } \\
\text { and gender }\end{array}$ & $\begin{array}{l}\text { OR }(95 \% \mathrm{Cl}) \text {, adjusted for } \\
\text { the other subscale (anxiety } \\
\text { or depression) }\end{array}$ & $\begin{array}{l}\text { OR }(95 \% \mathrm{Cl}) \text {, adjusted } \\
\text { for somatic symptoms } \\
\text { and diagnoses }\end{array}$ & $\begin{array}{l}\text { OR }(95 \% \mathrm{Cl}) \text {, fully } \\
\text { adjusted model }\end{array}$ \\
\hline \multicolumn{8}{|l|}{ Depression } \\
\hline Normal & $0-7$ & 54677 & 1788 & 1.00 (reference) & 1.00 (reference) & 1.00 (reference) & 1.00 (reference) \\
\hline Mild & 8-10 & 4647 & 332 & $1.43(1.26-1.63)$ & $1.43(1.24-1.64)$ & $1.35(1.17-1.55)$ & $1.27(1.10-1.46)$ \\
\hline Moderate & $11-14$ & 1753 & 157 & $1.75(1.45-2.11)$ & $1.70(1.39-2.08)$ & $1.55(1.26-1.90)$ & $1.43(1.16-1.75)$ \\
\hline Severe & $15-21$ & 272 & 32 & $2.49(1.63-3.79)$ & $2.29(1.48-3.56)$ & $1.96(1.24-3.10)$ & $1.71(1.08-2.71)$ \\
\hline Significance ${ }^{a}$ & & & & $<0.001$ & $<0.001$ & $<0.001$ & $<0.001$ \\
\hline \multicolumn{8}{|l|}{ Anxiety } \\
\hline Normal & $0-7$ & 51845 & 1957 & 1.00 (reference) & 1.00 (reference) & 1.00 (reference) & 1.00 (reference) \\
\hline Mild & $8-10$ & 6062 & 211 & $1.10(0.94-1.28)$ & $0.96(0.81-1.12)$ & $0.88(0.74-1.04)$ & $0.83(0.70-0.98)$ \\
\hline Moderate & $11-14$ & 2821 & 111 & $1.40(1.14-1.73)$ & $1.07(0.85-1.34)$ & $0.92(0.73-1.16)$ & $0.84(0.67-1.06)$ \\
\hline Severe & $15-21$ & 621 & 30 & $1.97(1.32-2.96)$ & $1.32(0.87-2.02)$ & $1.10(0.71-1.70)$ & $0.96(0.62-1.49)$ \\
\hline Significance ${ }^{a}$ & & & & $<0.001$ & $<0.453$ & $<0.375^{\mathrm{b}}$ & $<0.059^{\mathrm{b}}$ \\
\hline
\end{tabular}

1.08-2.71, in fully adjusted models, also adjusted for anxiety scale score). No similar significant dose-response pattern was found for anxiety when adjusted for age, gender and depression (Table 4).

\section{Effect modification by age, gender and somatic symptoms or diagnoses}

The effect of case-level anxiety and depression on mortality was equal in men and women (Table 5). Age moderated the effect of comorbid anxiety and depression on mortality $(P=0.017)$, effects being stronger in younger than older cohorts. A similar, but not statistically significant, tendency was found for anxiety and depression alone (Table 5). There were no statistically significant interactions between case-level anxiety/depression and level of somatic symptoms or diagnoses (data not shown).

\section{Discussion}

\section{Summary of results}

We found that case-level depression was a risk factor for mortality, robust for adjustment by a number of potential confounding or mediating factors, including somatic symptoms and diagnoses, physical impairment, physical activity, smoking, alcohol problems, educational level and socioeconomic status, blood pressure, cholesterol level and BMI (OR=1.37, 95\% CI 1.19-1.58). The association with anxiety scale scores was U-shaped. Adjusted for physical health, we found no association between case-level anxiety and mortality $(\mathrm{OR}=1.00)$. When comorbid with case-level depression, case-level anxiety was associated with a reduction in mortality. The association between comorbid anxiety and depression and mortality was equal in men and women, but significantly stronger in younger than older participants.

\section{Strengths and limitations}

The present study has several design strengths. The sample was large and comprehensively evaluated and the participation rate was reasonable considering the scale of the study. Ascertainment of mortality was complete (with the exception of emigration from the country) and ascertainment itself unlikely to have been influenced by exposure status.

There are some limitations to our study. Non-responders had on average poorer health than participants, reflected in higher mortality. ${ }^{7}$ Anxiety and depression at baseline were established using relatively brief screening instruments rather than clinical diagnosis, and with reference to the past 2 weeks only. Misclassification is likely to have been random; most likely resulting in an underestimate of the observed association. Since screening for psychiatric morbidity was limited to symptoms of anxiety and depression (and CAGE for alcohol problems) we cannot estimate the influence of other mental disorders nor rule out possible confounding by comorbidity.

As a result of the cross-sectional design, it is not possible to determine the temporal relationship between somatic health states and anxiety/depression. To the extent that mental disorders increase somatic conditions such as coronary heart disease, ${ }^{25}$ we

\begin{tabular}{|c|c|c|c|}
\hline & Anxiety only & Depression only & Both \\
\hline \multicolumn{4}{|l|}{ Age, years: OR $(95 \% \mathrm{Cl})$} \\
\hline $20-65$ & $1.27(0.94-1.72)$ & $1.79(1.31-2.45)$ & $1.91(1.43-2.55)$ \\
\hline$>65$ & $1.16(0.93-1.45)$ & $1.59(1.36-1.86)$ & $1.22(0.99-1.50)$ \\
\hline Significance of interaction by age ${ }^{a}$ & 0.427 & 0.779 & 0.017 \\
\hline \multicolumn{4}{|l|}{ Gender, OR (95\% Cl) } \\
\hline Men & $1.34(1.03-1.76)$ & $1.58(1.33-1.88)$ & $1.39(1.09-1.77)$ \\
\hline Women & $1.15(0.90-1.45)$ & $1.66(1.33-2.08)$ & $1.45(1.15-1.83)$ \\
\hline Significance of interaction by gender ${ }^{\mathrm{b}}$ & 0.364 & 0.654 & 0.794 \\
\hline
\end{tabular}


might be adjusting for mediating factors, causing underestimation of true effect sizes. On the other hand, we cannot rule out residual confounding from inadequately measured somatic illness causing common mental disorder. However, neither of the two are likely to explain the U-shaped association of anxiety with mortality.

Another limitation arises from the complex interrelationship between mental and somatic disorders and symptoms. Diagnostic criteria partly overlap between somatic illness and common mental disorder. We attempted to minimise this problem by employing the HADS (which includes no somatic symptoms of anxiety/depression) and then adjusting for somatic symptoms. This approach may miss 'masked depression', leading to underestimation of true effect sizes. The weighting procedure for physical conditions and symptoms sought to minimise the problem of residual confounding from somatic illness, but may have resulted in overadjustment of models and thus underestimation of the associations of interest. Residual confounding may have resulted from physical conditions not included in the lists, or from measurement error through underreporting of past or present illness. Another HUNT study analysis, for example, estimated 29\% underreporting of cancer. Underreporting, however, principally occurred in less severe conditions (e.g. underreporting for basal cell carcinoma $69 \%$ v. 3\% for breast cancer). We believe that this is most likely to have obscured rather than exaggerated the associations of interest. Finally, it is possible that cognitive impairments occurring in depression ${ }^{26}$ might increase underreporting in this group.

The fully adjusted models include variables for health-related behaviour and self-evaluated impairment, which all may form part of the expression of mental disorder, adding to the problem of overadjustment. However, the apparent influence of these 'lifestyle' covariates was relatively small on the associations of interest. The intervention aimed at the upper percentile of HADS total scores is unlikely to have had major effects, ${ }^{9}$ but could in theory have deflated observed effect sizes.

\section{How strong is the association between depression and mortality?}

Previous research has been criticised because studies have not always fully accounted for relevant confounders. ${ }^{3,4}$ In this analysis, we included an extensive list of physical symptoms and disorders, weighted for their associations with mortality in this sample. Despite the risk of 'overadjustment', these covariates still accounted for less than a quarter of the association between depression and mortality. The inclusion of physical impairment, health-related behaviour, socioeconomic factors and physical measures in regression models further attenuated this association but, in the fully adjusted model, it remained highly significant and of reasonable strength. Our estimate of the association between depression and mortality is, adjusted for age and gender only, comparable with that reported in recent meta-analyses, ${ }^{27-29}$ but weaker after full adjustment for confounding factors. This discrepancy might be a consequence of poor adjustment for relevant confounders in studies included in meta-analyses. On the other hand, the adjustments in the present paper may be overextensive as discussed previously, which might lead us to underestimate the true association. The composition of the HADS and our choice of cut-off may also contribute to a weaker association. The HADS is particularly designed to avoid false positives in the context of comorbid somatic disease, and therefore omitted somatic symptoms of depression and anxiety. ${ }^{9}$ To illustrate the strength of the association between depression and mortality, we compared it with the effect of current smoking: an accepted risk factor for mortality and a target for major public health initiatives. The odds ratios for mortality associated with smoking and depression were comparable in the models adjusted for age and gender only, and the association with depression actually exceeded that of smoking in the fully adjusted model. This illustrates the potential importance of depression as a risk factor for mortality - however, causal pathways require further consideration.

\section{Mechanisms underlying the depression-mortality association}

The study adds to the present knowledge of mechanisms linking depression with mortality. The strongest attenuation of the association was found following adjustment for somatic symptoms and diagnoses, which supports confounding by physical disease as a partial explanation. ${ }^{30}$ The second strongest attenuation of association was found following adjustment for physical impairment. This might indicate confounding if the depressed state is a reaction to the impairment. ${ }^{31}$ However, the physical impairment might be an epiphenomenon of depression: if so, part of the attenuation may represent a causal pathway between depression and mortality and inclusion of this variable in the model may contribute to overadjustment, leaving the association with depression underestimated. Physical activity was the third strongest explanatory variable which, conceptually, is more likely to be a mediating than confounding factor and supports a lifestyle hypothesis regarding the causal pathway between depression and mortality. ${ }^{32}$ Factors not accounting for the association are also relevant for the consideration of mechanisms. These included smoking, alcohol problems, educational level and socioeconomic status, BMI, diastolic blood pressure and total cholesterol level. This is somewhat surprising as for example smoking and physical activity are factors reported to be associated with both mortality and depression. Mediation via other biological changes secondary to depression cannot be rejected.

\section{Cardiovascular disease mortality in depression}

Most of the literature on mortality and depression has focused on cardiovascular disease mortality. ${ }^{31,33}$ Despite some controversy over the evidence for this association, potential mechanisms have been suggested. ${ }^{34}$ In a previous analysis of the same dataset, we recently found that depression was no stronger a risk factor for cardiovascular disease mortality than for other causes combined. ${ }^{7}$ The analysis described here did not specifically address cardiovascular disease mortality. Despite strong evidence for associations between smoking and depression, ${ }^{18}$ adjustment for smoking had little impact on the association of interest. Adjustment for blood pressure also did little to the association, which is understandable in light of recent evidence that its relation to depression may be negative. ${ }^{35}$ Cholesterol level also failed to account for the association.

\section{No gender difference, but stronger mortality association in younger participants}

Our finding of no gender difference in the association between depression and mortality contrasts with the previously reported stronger effect in men than in women. ${ }^{6,36,37}$ The stronger effect of depression on mortality in younger individuals than older has not previously been reported, but the same direction of interaction was found for disability pension award as an outcome in this sample. ${ }^{38}$ Severe somatic conditions such as cancer and cardiovascular diseases increase strongly with age, perhaps decreasing the relative contribution of risk factors of relevance across all age groups. 


\section{Anxiety and mortality}

The literature on anxiety and mortality is relatively sparse compared with that on depression. Previous studies have reported conflicting findings concerning the association between anxiety levels and mortality, which has been reported as positive, ${ }^{39}$ absent, ${ }^{6,40,41}$ and negative. ${ }^{5,42}$ Our findings support the last. We speculate that confounding by comorbid depression, and the use of statistical models not allowing non-linear effects, might explain some of the controversy in the literature. Treating the symptom scale as a continuous variable, our findings of a negative association between anxiety symptoms and mortality are consistent with the largest study employing the HADS. ${ }^{5}$ Furthermore, we found lower mortality in participants with comorbid case-level anxiety and depression compared with those with case-level depression alone. The latter finding is counterintuitive, since comorbid anxiety and depression are associated with both poorer physical health ${ }^{43}$ and more disability ${ }^{38}$ than depression alone. We speculate that low trait anxiety may result in reduced help-seeking and reduced adherence to treatment when somatic illness occurs, ${ }^{34}$ and perhaps also to more risk behaviour with a corresponding increased risk of accidental deaths in early adulthood. ${ }^{42}$ In other words, there may be an evolutionary advantage of moderate levels of anxiety, a hypothesis that requires further evaluation. These findings of differences between anxiety and depression appear to be relatively rare for a given outcome and might be an argument for maintaining the separation of the two 'disorders': hence a contribution to the debate on cothymia. ${ }^{44}$ The HADS anxiety scale score is negatively associated with both cardiovascular disease mortality and other causes combined, ${ }^{7}$ perhaps precluding hypotheses relating to specific causes of death. Confounding is also unlikely since there was no apparent alteration following adjustment for the large number of covariates available for this analysis.

Beyond case-levels, we found a U-shaped association between overall anxiety symptom load and mortality, with relatively high mortality associated with both low and high levels of symptoms - although most pronounced for low symptoms. In terms of population attributable fractions, the effect of low anxiety (the first quartile compared with the third quartile) appeared to be surprisingly strong compared with case-level depression (population attributable fractions 0.077 v. 0.013), which is a consequence of first quartile anxiety being a seven times more prevalent category than case-level depression. In other words, relatively low levels of anxiety potentially accounted for substantially more mortality than did case-level depression. Further research is required to clarify underlying mechanisms: perhaps specifically to investigate whether modest levels of anxiety promote earlier identification and treatment of potentially lifethreatening disease ${ }^{34}$ and/or decrease risk behaviour associated with non-disease mortality. ${ }^{42}$

Arnstein Mykletun, PhD, Research Centre for Health Promotion, Faculty of Psychology, University of Bergen, Norway, and Institute of Psychiatry, King's College London, UK and Norwegian Institute of Public Health, Division of Mental Health, Oslo, Norway; Ottar Bjerkeset, MD, PhD, Department of Research and Development, Levanger Hospital, Norway, and Department of Neuroscience, Unit for Psychiatry and Behavioral Science, Faculty of Medicine, National University of Science and Technology, Trondheim, Norway; Simon øverland, PhD, Research Centre for Health Technology, Trondheim, Norway; Simon Øverland, PhD, Research Centre for Health
Promotion, Faculty of Psychology, University of Bergen, Norway; Martin Prince, MD, MRCPsych, PhD, Michael Dewey, PhD, Robert Stewart, MD PhD, Institute of Psychiatry, King's College London, UK

Correspondence: Arnstein Mykletun, Mental Health Epidemiology, Research Centre of Health Promotion, Faculty of Psychology, University of Bergen, Christiesgt 13 N-5015 Bergen, Norway. Email: Arnstein.Mykletun@uib.no

First received 13 May 2008, final revision 12 Jan 2009, accepted 11 Feb 2009

\section{Funding}

R.S. is funded by NIHR Biomedical Research Centre for Mental Health, the South London and Maudsley NHS Trust, and the Institute of Psychiatry, King's College London.

\section{Acknowledgements}

Data were obtained from the Norwegian Office for Social Insurance and The Nord-Trøndelag Health Study (The HUNT Study, a collaboration between HUNT Research Centre, Faculty of Medicine, Norwegian University of Science and Technology (NTNU, Verdal), Norwegian Institute of Public Health, and Nord-Trondelag County Council). Professor Alv A. Dahl is acknowledged for his facilitation in the planning of the study, and Professor Leif Edvard Aarg is acknow for his facilation in the planning of the study, and Professor Leif Edvard Aarø is acknowledged for careful advice. Arnstein Mykletun holds a career research grant from the Norwegian Research Council.

\section{References}

1 Cuijpers P, Schoevers RA. Increased mortality in depressive disorders: a review. Curr Psychiatry Rep 2004; 6: 430-7.

2 Gallo J, Bogner H, Morales K, Post E, Lin J, Bruce M. The effect of a primary care practice-based depression intervention on mortality in older adults: a randomized trial. Ann Intern Med 2007; 146: 10

3 Cole MG. Does depression in older medical inpatients predict mortality? A systematic review. Gen Hosp Psychiatry 2007; 29: 425-30.

4 Saz P, Dewey ME. Depression, depressive symptoms and mortality in persons aged 65 and over living in the community: a systematic review of the literature. Int J Geriatr Psychiatry 2001; 16: 622-30.

5 Herrmann C, Brand-Driehorst S, Buss U, Ruger U. Effects of anxiety and depression on 5-year mortality in 5057 patients referred for exercise testing. J Psychosom Res 2000; 48: 455-62.

6 Holwerda TJ, Schoevers RA, Dekker J, Deeg DJH, Jonker C, Beekman ATF. The relationship between generalized anxiety disorder, depression and mortality in old age. Int J Geriatr Psychiatry 2007; 22: 241-9.

7 Mykletun A, Bjerkeset O, Dewey M, Prince M, Overland S, Stewart R. Anxiety, depression and cause specific mortality. The HUNT study. Psychosom Med 2007; 69: 323-31.

8 Holmen J, Midthjell K, Krüger O, Langhammer A, Holmen T, Bratberg G, et al. The Nord-Trøndelag Health Study 1995-97 (HUNT 2): objectives, contents, method and participation. Norsk Epidemiologi 2003; 13: 19-32.

9 Zigmond AS, Snaith RP. The Hospital Anxiety and Depression Scale. Acta Psychiatr Scand 1983; 67: 361-70.

10 Bjerkeset O, Dahl AA, Stordal E, Dahl NH, Kruger MB, Linaker O. Feasibility of mental health screening and intervention in the HUNT population study. Soc Psychiatry Psychiatr Epidemiol 2006; 41: 191-8.

11 Bjerkeset O, Mykletun A, Dahl AA, Linaker O. Mortality in relation to selfreported mixed anxiety and depression symptoms: the HUNT study. Nord J Psychiatry 2007; 61: 6-11.

12 Mykletun A, Stordal E, Dahl AA. Hospital Anxiety and Depression (HAD) scale: factor structure, item analyses and internal consistency in a large population. Br J Psychiatry 2001; 179: 540-4.

13 American Psychiatric Association. Diagnostic and Statistical Manual of Mental Disorders (3rd edn) (DSM-III). APA, 1980.

14 American Psychiatric Association. Diagnostic and Statistical Manual of Mental Disorders (4th edn) (DSM-IV). APA, 1994.

15 World Health Organization. International Statistical Classification of Diseases and Related Health Problems (ICD-8). WHO, 1967.

16 World Health Organization. International Statistical Classification of Diseases and Related Health Problems (ICD-9). WHO, 1978.

17 Bjelland I, Dahl AA, Haug TT, Neckelmann D. The validity of the Hospital Anxiety and Depression Scale. An updated literature review. J Psychosom Res 2002; 52: 69-77.

18 Mykletun A, Overland S, Aaro LE, Liabø HM, Stewart R. Smoking in relation to anxiety and depression. Evidence from a large population survey, the HUNTStudy. Eur Psychiatry 2008; 23: 77-84.

19 Aertgeerts $B$. The value of the CAGE in screening for alcohol abuse and alcohol dependance in general clinical populations: a diagnostic metaanalysis. J Clin Epidemiol 2004; 57: 30-9.

20 Aertgeerts $B$. The value of the CAGE in screening for alcohol abuse and alcohol dependance in general clinical populations: a diagnostic metaanalysis. J Clin Epidemiol 2004; 57: 30-9.

21 Roness A, Mykletun A, Dahl AA. Help-seeking behaviour in patients with anxiety disorder and depression. Acta Psychiatr Scand 2005; 111: 51-8. 
22 Krokstad S, Westin S. Health inequalities by socioeconomic status among men in the Nord-Trondelag Health Study, Norway. Scand J Public Health 2002; 30: 113-24.

23 Hildrum B, Mykletun A, Stordal E, Bjelland I, Dahl AA, Holmen J. Association of low blood pressure with anxiety and depression: the Nord-Trondelag Health Study. J Epidemiol Community Health 2007; 61: 53-8.

24 Weich S, Prince M. Cohort studies. In Practical Psychiatric Epidemiology (eds Prince M, Stewart R, Ford T, Hotopf M): 13-41. Oxford University Press, 2003.

25 Carney RM, Sheps DS. Depression is a risk factor for mortality in coronary heart disease. Psychosom Med 2004; 66: 799-801.

26 Biringer E, Mykletun A, Dahl AA, Smith AD, Engedal K, Nygaard HA, et al. The association between depression, anxiety, and cognitive function in the elderly general population: the Hordaland Health Study. Int J Geriatr Psychiatry 2005; 20: 989-97.

27 Barth J, Schumacher M, Herrmann-Lingen C. Depression as a risk factor for mortality in patients with coronary heart disease: a meta-analysis. Psychosom Med 2004; 66: 802-13.

28 Cuijpers $\mathrm{P}$, Smit $\mathrm{H}$. Excess mortality in depression: a meta-analysis of community studies. J Affect Disord 2002; 72: 227-36.

29 van Melle JP, de Jonge P, Spijkerman TA, Tijssen JGP, Ormel J, van Veldhuisen DJ, et al. Prognostic association of depression following myocardial infarction with mortality and cardiovascular events: a meta-analysis. Psychosom Med 2004; 66: 814-22.

30 Carney RM, Freedland $\mathrm{KE}$, Jaffe AS. Depression as a risk factor for coronary heart disease mortality - Commentary. Arch Gen Psychiatry 2001; 58: 229-30.

31 Wulsin LR, Vaillant GE, Wells VE. A systematic review of the mortality of depression. Psychosom Med 1999; 61: 6-17.

32 Abas $M$, Hotopf $M$, Prince $M$. Depression and mortality in a high-risk population: 11-year follow-up of the Medical Research Council Elderly Hypertension Trial. Br J Psychiatry 2002; 181: 123-8.

33 Lett $H$, Blumenthal J, Babyak $M$, Sherwood A, Strauman T, Robins $C$, et al. Depression as a risk factor for coronary artery disease: evidence, mechanisms, and treatment. Psychosom Med 2004; 66: 11.
34 Carney RM, Freedland KE, Miller GE, Jaffe AS. Depression as a risk factor for cardiac mortality and morbidity: a review of potential mechanisms. J Psychosom Res 2002; 53: 897-902.

35 Hildrum B, Mykletun A, Holmen J, Dahl AA. Effect of anxiety and depression on blood pressure: 11-year longitudinal population study. Br J Psychiatry 2008; 193: 108-13.

36 Zheng DY, Macera CA, Croft JB, Giles WH, Davis D, Scott WK. Majo depression and all cause mortality among white adults in the United States. Ann Epidemiol 1997; 7: 213-8.

37 Schoevers RA, Geerlings MI, Beekman ATF, Penninx BWJH, Deeg DJH, Jonker $\mathrm{C}$, et al. Association of depression and gender with mortality in old age. Results from the Amsterdam Study of the Elderly (AMSTEL). $\mathrm{Br} J$ Psychiatry 2000; 177: 336-42.

38 Mykletun A, Overland S, Dahl AA, Krokstad S, Bjerkeset O, Glozier N, et al A population-based cohort study of the effect of common mental disorders on disability pension awards. Am J Psychiatry 2006; 163: 1412-8.

39 Grasbeck A, Rorsman B, Hagnell O, Isberg PE. Mortality of anxiety syndromes in a normal population: the Lundby study. Neuropsychobiology 1996; 33 118-26.

40 Lavretsky H, Mistry R, Bastani R, Gould R, Gokhman I, Huang D, et al. Symptoms of depression and anxiety predict mortality in elderly veterans enrolled in the UPBEAT program. Int J Geriatr Psychiatry 2003; 18: 183-4.

41 Lane D, Carroll D, Ring C, Beevers DG, Lip GY. Mortality and quality of life 12 months after myocardial infarction: effects of depression and anxiety. Psychosom Med 2001; 63: 221-30.

42 Lee WE, Wadsworth ME, Hotopf M. The protective role of trait anxiety: a longitudinal cohort study. Psychol Med 2006; 36: 345-51.

43 Stordal E, Bjelland I, Dahl AA, Mykletun A. Anxiety and depression in individuals with somatic health problems. The Nord-Trondelag Health Study (HUNT). Scand J Prim Health Care 2003; 21: 136-41.

44 Tyrer $\mathrm{P}$. The case for cothymia: mixed anxiety and depression as a single diagnosis. Br J Psychiatry 2001; 179: 191-3. 